\title{
Pedigree analysis of eight Spanish beef cattle breeds
}

\author{
Juan Pablo Gutiérrez ${ }^{\mathrm{a} *}$, Juan Altarriba ${ }^{\mathrm{b}}$, \\ Clara DíAz ${ }^{\mathrm{c}}$, Raquel QuintANILlA ${ }^{\mathrm{d} * *}$, \\ Javier CAÑón ${ }^{\mathrm{a}}$, Jesús PIEDRAFITA ${ }^{\mathrm{d}}$ \\ ${ }^{a}$ Departamento de Producción Animal, Facultad de Veterinaria, \\ Universidad Complutense de Madrid, 28040 Madrid, Spain \\ ${ }^{\text {b }}$ Departamento de Anatomía y Genética, Facultad de Veterinaria, \\ Universidad de Zaragoza, 50013 Zaragoza, Spain \\ c Departamento de Mejora Genética Animal, INIA, Carretera de la Coruña, \\ $\mathrm{Km}$ 7, 28040 Madrid, Spain \\ d Departament de Ciència Animal i dels Aliments, Facultat de Veterinària, \\ Universitat Autònoma de Barcelona, \\ 08193 Bellaterra, Barcelona, Spain
}

(Received 16 November 2001; accepted 7 August 2002)

\begin{abstract}
The genetic structure of eight Spanish autochthonous populations (breeds) of beef cattle were studied from pedigree records. The populations studied were: Alistana and Sayaguesa (minority breeds), Avileña - Negra Ibérica and Morucha ("dehesa" breeds, with a scarce incidence of artificial insemination), and mountain breeds, including Asturiana de los Valles, Asturiana de la Montaña and Pirenaica, with extensive use of AI. The Bruna dels Pirineus breed possesses characteristics which make its classification into one of the former groups difficult. There was a large variation between breeds both in the census and the number of herds. Generation intervals ranged from 3.7 to 5.5 years, tending to be longer as the population size was larger. The effective numbers of herds suggest that a small number of herds behaves as a selection nucleus for the rest of the breed. The complete generation equivalent has also been greatly variable, although in general scarce, with the exception of the Pirenaica breed, with a mean of 3.8. Inbreeding effective population sizes were actually small (21 to 127), especially in the mountain-type breeds. However, the average relatedness computed for these breeds suggests that a slight exchange of animals between herds will lead to a much more favourable evolution of inbreeding. The effective number of founders and ancestors were also variable among breeds, although in general the breeds behaved as if they were founded by a small number of animals (25 to 163 ).
\end{abstract}

beef breeds / inbreeding / probability of gene origin / conservation

\footnotetext{
* Correspondence and reprints

E-mail: gutgar@vet.ucm.es

** Present address: Station de génétique quantitative et appliquée, Inra, 78352 Jouy-en-Josas Cedex, France
} 


\section{INTRODUCTION}

Domestic animal diversity is an integral part of global biodiversity, which requires sound management for its sustainable use and future availability [19]. The knowledge of genetic diversity of the population is the basis for effective selection and/or conservation programmes. According to Vu Tien Khang [22], genetic variability can be studied through the estimation of the genetic variance of quantitative traits, the analysis of pedigree data and the description of visible genes and markers in the population, such as microsatellite markers. Demographic analysis allows us to describe the structure and dynamics of populations considered as a group of renewed individuals. Genetic analysis is interested in the evolution of the population's gene pool. Since the history of genes is fully linked to that of individuals, demography and population genetics are complementary matters. Pedigree analysis is an important tool to describe genetic variability and its evolution across generations. The trend in inbreeding has been the most frequently used parameter to quantify the rate of genetic drift. Inbreeding depresses the components of reproductive fitness in naturally outbreeding species [10]. In beef cattle, the effects of inbreeding were relatively minor at lower levels of inbreeding, and animals that had inbreeding coefficients higher than $20 \%$ were more affected by inbreeding than those having milder levels of inbreeding (see review of Burrow, [5]).

There is a direct relationship between the increase in inbreeding and the decrease in heterozygosity for a given locus in a closed, unselected and panmictic population of finite size [24]. In domestic animal populations, however, some drawbacks may arise with this approach [4]. A complementary approach is to analyse the probabilities of gene origin $[12,22]$. In this method, the genetic contribution of the founders, i.e., the ancestors with unknown parents, of the current population is measured. As proposed by Lacy [13], these founder contributions could be combined to derive a synthetic criterion, the "founder equivalents". In addition, Boichard et al. [4] have proposed to compute the effective number of ancestors that accounts for the bottlenecks in a pedigree.

Compared to the number of European beef cattle breeds, there are only a few studies regarding the genetic structure of European local beef cattle populations and most of them concern only one breed or a small number of breeds $[1,4,8,20]$. Furthermore, some of the Spanish populations have started programmes of genetic evaluation through the BLUP animal model methodology. Verrier et al. [21] have argued that the use of the animal model in populations of limited effective size leads to profound changes in the structure of the population and cannot be the optimum selection criterion neither in terms of the cumulated genetic progress or maintenance of genetic variability. In this context, the objective of this study was to analyse the herdbooks in order to know the gene flows, population structure and potential 
danger for losing genetic variability of eight Spanish local beef cattle breeds. Population structures were analysed in terms of census, generation interval, effective number of herds, pedigree completeness level, inbreeding coefficient, average relatedness, effective population size and effective number of founders, ancestors and founder herds.

\section{MATERIALS AND METHODS}

\subsection{Breeds and data available}

Eight Spanish breeds were involved in this analysis: Alistana (Ali), Asturiana de la Montaña (AM), Asturiana de los Valles (AV), Avileña - Negra Ibérica (A-NI), Bruna dels Pirineus (BP), Morucha (Mo), Pirenaica (Pi) and Sayaguesa (Say). Herdbook data available from the foundation up to the year 1996 were used for this study. Data registered in the herdbook were assumed to be representative of the whole breed although, for most of the breeds, registered animals represent only a low percentage of the population.

These breeds are different in many aspects but, in order to discuss the results, they were classified into three main groups. The first one was composed of minority breeds: Ali and Say, with fewer than 500 registered calves per year. A second group, the mountain breeds (AM, AV, and Pi), was defined as those with a geographical location in mountain areas and wide use of some animals as parents, usually by artificial insemination (AI). The third group was the "dehesa" breeds, and was made up of A-NI and Mo. The BP breed should have been classified into the group of mountain breeds, but due to the scarce use of $\mathrm{AI}$ and its sparse pedigree knowledge, this breed cannot be properly assigned to any of the previous groups.

\subsection{Analysis of pedigree structure and inbreeding}

The objective of this part was to obtain significant insight in the recent genetic and current status of the breeds regarding breeding practices and effective population sizes. The work was carried out from two main points of view: inbreeding and analysis of the founders. Specific FORTRAN codes were written to compute all of the parameters shown below.

\subsubsection{Generation interval}

It is defined as the average age of parents when their progeny, upon becoming parents themselves, are born. It is computed only for the animals who are parents in the four years previous to the last year analysed. In order to know the evolution of this parameter, generation intervals were also computed with the same criteria from a sample of animals born ten years before in a block of four consecutive years. 


\subsubsection{Effective number of herds}

Robertson [17] defined the $C_{S}$ parameter as the probability that two animals taken at random, have the sire in the same herd. We can, in a similar way, obtain the $C_{S S}$ parameter to give the probability for sires of sires, and successively the $C_{S S S}$ parameter, and so on. The inverse of these values $\left(H_{S}, H_{S S}, \ldots\right)$ will be the effective number of herds supplying sires, grand sires, great-grandsires, and so on.

\subsubsection{Pedigree description}

Average inbreeding coefficients vary among breeds for several reasons that may lead to difficult interpretations. The most important reasons are the size of the population, pedigree completeness level, and breeding policy. Among them, pedigree completeness level is the cause that could make drawing conclusions from the available data difficult. Two ways were used to describe the pedigree completeness level: (1) computing the proportion of parents, grandparents and great-grandparents known and (2) estimating the complete generation equivalent value $[3,4]$. This parameter was estimated in each breed by averaging over the sum of $(1 / 2)^{n}$, where $n$ is the number of generations separating the individual from each known ancestor.

\subsection{Inbreeding coefficient}

The inbreeding coefficient of an individual $(F)$ is the probability of having two genes which are identical by descent [23]. A modification of the Meuwissen and Luo [15] algorithm was used to compute the inbreeding coefficients.

\subsubsection{Average relatedness}

Inbreeding is a consequence of mating relatives, but this parameter does not explain the reason for this kind of mating. Average relatedness (AR) [9] among all animals in the population tends to be higher too, when all animals are highly related and there is no chance of mating unrelated or slightly related individuals. Nevertheless, a low average relatedness coupled with a high average inbreeding suggests a wide use of within-herd matings. $A R$ coefficients were chosen because this parameter provides complementary information to that provided by the inbreeding coefficient.

The average relatedness [9] of each individual is the average of the coefficients in the row corresponding to the individual in the numerator relationship matrix (A). $A R$ has been preferred to the mean kinship parameter [2] because it is much easier to compute and both parameters show basically the same concept for practical purposes. However, $A R$ indicates the percentage of representation 
of each animal in a whole pedigree, while mean kinship is not useful for description purposes.

The average inbreeding coefficient of a population is frequently used as a measure of its level of homozygosity. All of the information on inbreeding coefficients is included in the diagonal elements of the numerator relationship matrix. If, for instance, there is a subdivision of the population, animals are mated within subpopulations and a decrease in inbreeding coefficients might be possible by mating animals from different families. Furthermore, the $A R$ coefficient also addresses the chance of recovery of the breed, since it also takes coancestry coefficients into account, not only for the animals of the same generation but also for those of previous generations whose genetic potential could be interesting to preserve.

\subsubsection{Effective population size}

The effective size of a population $\left(N_{e}\right)$ is defined as the size of an idealised population which would give rise to the rate of inbreeding $(\Delta F)$. The effective population size was calculated as in Wright [23]:

$$
N_{e}=\frac{1}{2 \Delta F}
$$

where $\Delta F$ is the relative increase in inbreeding by generation. This formula, however, usually fits poorly to real populations, giving an overestimate of the actual effective population size [4], mainly when the degree of pedigree knowledge is scarce.

The relative increase in inbreeding by generation $(\Delta F)$, i.e., the relative decrease of heterozygosity between two generations, was defined following Wright [24] as:

$$
\Delta F=\frac{F_{n}-F_{n-1}}{1-F_{n-1}}
$$

$F_{i}$ being the average inbreeding in the $i$ th generation.

The increase in inbreeding between two generations $\left(F_{n}-F_{n-1}\right)$ was obtained from the regression coefficient $(b)$ of the average inbreeding over the year of birth obtained in the last 8 years, and considering the average generation interval $(\ell)$ as follows:

$$
F_{n}-F_{n-1}=\ell \times b
$$

$F_{n-1}$ being computed from the mean inbreeding in the last year studied $\left(F_{l y}\right)$ as:

$$
F_{n-1}=F_{l y}-\ell \times b .
$$




\subsubsection{Effective number of founders and effective number of ancestors}

When we wish to describe the population structure after a small number of generations, parameters derived from the probability of gene origin are very useful [4]. These parameters can detect recent significant changes in breeding strategy, before their consequences appear in terms of inbreeding increase. The parameters are useful both when the breeding objective is the maintenance of a gene pool (conservation programmes), and when analysing the consequences of selection in small populations.

The effective number of founders, $f_{e}$ [13], is the number of equally contributing founders that would be expected to produce the same genetic diversity as in the population under study. It is computed as:

$$
f_{e}=\frac{1}{\sum_{k=1}^{f} q_{k}^{2}}
$$

where $q_{k}$ is the probability of gene origin of the $k$ ancestor. The effective number of ancestors $\left(f_{a}\right)$ is the minimum number of ancestors, founders or not, necessary to explain the complete genetic diversity of the population under study [3]. For this purpose a reference population was defined as the animals born in three consecutive and significant years (1993-1995). The effective number of ancestors was computed by following the algorithm described by Boichard et al. [4].

\subsubsection{Effective number of founder herds}

Finally, the initial contribution of founders can be added into each herd founder contribution, and the inverse of their added squared value gives an effective number of founder herds.

\section{RESULTS}

\subsection{Census}

Table I shows the evolution of some demographic parameters in the analysed breeds: the number of cows registered in the breed association (when this parameter was available), number of calves born, number of herds recording calvings, and calves/herd rate. This table shows that recording began during the last decade, with the exception of Pi and A-NI. In general, the breeds tended to increase their census over time. The apparent decrease in the Mo census must be interpreted as a delay in the registering of cows at the time of the study. 
Table I. Evolution of the number of registered cows, number of registered calves, number of herds (left) and calves/herd (right) in eight Spanish beef cattle breeds.

\begin{tabular}{|c|c|c|c|c|c|c|c|c|c|c|c|c|}
\hline \multirow[t]{2}{*}{ Breed } & \multicolumn{3}{|c|}{$\begin{array}{c}\text { Number } \\
\text { of registered cows }\end{array}$} & \multicolumn{3}{|c|}{$\begin{array}{c}\text { Number } \\
\text { of registered calves }\end{array}$} & \multicolumn{6}{|c|}{$\begin{array}{c}\text { Number } \\
\text { of herds (calves/herd) }\end{array}$} \\
\hline & 1985 & 1990 & 1995 & 1985 & 1990 & 1995 & & 985 & 199 & & 19 & 95 \\
\hline Ali & - & - & - & 104 & 184 & 157 & 9 & 11.6 & 5 & 36.8 & 6 & 26.2 \\
\hline $\mathrm{AM}$ & - & 1809 & 4629 & 233 & 508 & 1075 & 106 & 2.2 & 182 & 2.8 & 204 & 5.3 \\
\hline $\mathrm{AV}$ & - & 1554 & 7863 & 1948 & 3320 & 6310 & 970 & 2.0 & 1411 & 2.4 & 1798 & 3.5 \\
\hline A-NI & 2506 & 4009 & 4060 & 2535 & 4125 & 4841 & 49 & 51.7 & 115 & 35.9 & 104 & 46.5 \\
\hline BP & - & 2061 & 2809 & - & 824 & 1707 & - & - & 140 & 6.0 & 102 & 18.2 \\
\hline Mo & 4289 & - & - & 912 & 869 & - & 104 & 8.8 & 90 & 9.7 & - & - \\
\hline $\mathrm{Pi}$ & 12823 & 11892 & 13117 & 2376 & 2949 & 5019 & 558 & 4.3 & 541 & 5.4 & 486 & 10.3 \\
\hline Say & - & - & - & 53 & 57 & 64 & 9 & 5.9 & 10 & 5.7 & 11 & 5.8 \\
\hline
\end{tabular}

Population size, estimated as the number of calves born in a year, showed a wide range of variation among breeds. For instance, in 1995 calving recording in the Say breed reached 64 animals, while AV records were up to a hundred times this number (6310). There are breeds still growing in the number of calving records, as in AM, AV, Pi, and Say, while there are other breeds which remain in an approximate constant number (Ali, A-NI, BP, Mo). The evolution of the census reflects which breeds are still growing.

There were some breeds where the number of herds tended to decrease while the number of calves increased or remained constant (A-NI, Pi), showing an increase in the herd size. The calves/herd rate reflects herd size and is particularly interesting in terms of breeding management. A large dehesa population with a relatively long history, like A-NI, had a very high value showing that the herd size is greater than in other breeds.

\subsection{Generation interval}

Generation intervals for the four last effective years of recording and for four other consecutive years, ten years before the first four used, are presented in Table II. The estimates ranged from 3.70 to 6.08 years in the reference populations. In the sire-offspring pathway, the generation interval was always lower because sires were replaced early and, so, the AM and AV breeds tend to present greater differences with respect to those intervals ten years before, because of the introduction and widespread use of artificial insemination.

In addition, the longest generation intervals corresponded to the largest populations, perhaps due to the need of quickly replacing breeding animals in small populations. The values estimated in the minority breeds, however, 
Table II. Generation intervals (years) estimated from the parents of the calf-crop for the years 1985 and 1995 in eight Spanish beef cattle breeds.

\begin{tabular}{|c|c|c|c|c|c|c|c|c|c|c|}
\hline & \multicolumn{2}{|c|}{ Sire/Son } & \multicolumn{2}{|c|}{ Sire/Daughter } & \multicolumn{2}{|c|}{ Dam/Son } & \multicolumn{2}{|c|}{ Dam/Daughter } & \multicolumn{2}{|c|}{ Average } \\
\hline & 1985 & 1995 & 1985 & 1995 & 1985 & 1995 & 1985 & 1995 & 1985 & 1995 \\
\hline Ali & 3.07 & 3.11 & 2.94 & 3.09 & 6.23 & 5.69 & 5.69 & 5.51 & 4.04 & 4.08 \\
\hline AM & 4.65 & 3.49 & 3.85 & 3.66 & 7.31 & 4.81 & 7.33 & 5.57 & 5.88 & 4.55 \\
\hline $\mathrm{AV}$ & 4.09 & 3.22 & 4.06 & 3.26 & 6.10 & 4.91 & 6.32 & 5.00 & 5.28 & 4.31 \\
\hline A-NI & 4.10 & 3.60 & 4.20 & 3.60 & 4.30 & 3.80 & 4.50 & 3.90 & 4.30 & 3.70 \\
\hline BP & - & 5.20 & - & 4.45 & - & 6.49 & - & 5.94 & - & 5.52 \\
\hline Mo & 4.52 & 4.37 & 4.57 & 4.01 & 6.38 & 4.52 & 5.47 & 4.57 & 4.93 & 4.76 \\
\hline $\mathrm{Pi}$ & 7.75 & 5.02 & 6.61 & 4.49 & 8.52 & 7.26 & 7.48 & 7.09 & 7.39 & 6.08 \\
\hline Say & 2.87 & 2.86 & 2.68 & 3.35 & 6.40 & 4.00 & 5.75 & 4.21 & 4.07 & 3.75 \\
\hline
\end{tabular}

must be observed with caution due to the small number of records used in their computation. Furthermore, generation intervals were shorter than those estimated with data obtained ten years before. Among other causes, this difference could be due to an improvement of reproductive management, shorter longevity and the use of genetic evaluations for replacement decisions.

\subsection{Effective number of herds}

The actual and effective number of herds supplying sires $\left(H_{S}\right)$, grand-sires $\left(H_{S S}\right)$, and great-grandsires $\left(H_{S S S}\right)$ are shown in Table III. In general, the effective number of herds was smaller than the actual number of herds in all breeds. This means that an unbalanced contribution of the herds to the gene pool exists, since a small number of herds behave as a selection nucleus supplying sires to the rest of the population.

Whereas the actual number of herds supplying ancestors decreases with the number of generations considered, the effective number of herds tends to remain almost constant in many of the breeds, leading one to think that the herds supplying the genetic stock are always the same.

\subsection{Pedigree structure}

An indepth analysis of the pedigree completeness level of the breeds is important since all results in terms of inbreeding and relationship are dependent upon it. The percentages of parents, grandparents and great-grandparents known are shown in Figure 1. The breed with the highest pedigree completeness level was Pi followed by A-NI, both in terms of the complete generation equivalent (Tab. IV) and also the percentage of known ancestors in the most recent 
Table III. Actual and effective number of herds contributing sires $\left(H_{S}\right)$, grand-sires $\left(H_{S S}\right)$ and great-grandsires $\left(H_{S S S}\right)$, following the Robertson (1953) methodology in eight Spanish beef cattle breeds.

\begin{tabular}{lrrrrrrrr}
\hline & \multicolumn{2}{c}{ Sires } & & \multicolumn{2}{c}{ Grandsires } & & \multicolumn{2}{c}{ Great-grandsires } \\
\cline { 2 - 3 } \cline { 8 - 9 } & Actual & $H_{S}$ & & Actual & $H_{S S}$ & & Actual & $H_{S S S}$ \\
\hline Ali & 14 & 3 & & 13 & 4 & & 9 & 4 \\
AM & 303 & 77 & & 293 & 75 & & 272 & 74 \\
AV & 2636 & 631 & & 2472 & 692 & & 1990 & 548 \\
A-NI & 61 & 13 & & 39 & 7 & & 23 & 3 \\
BP & 41 & 10 & & 15 & 3 & & & \\
Mo & 218 & 89 & & 198 & 90 & & 167 & 81 \\
Pi & 1813 & 341 & & 1741 & 353 & & 1655 & 349 \\
Say & 16 & 6 & & 14 & 6 & & 12 & 5 \\
\hline
\end{tabular}

Table IV. Estimates of average inbreeding and average relatedness in eight Spanish beef cattle breeds.

\begin{tabular}{lccc|cc}
\hline Breed & $\begin{array}{c}\text { Complete } \\
\text { equivalent } \\
\text { generations }\end{array}$ & $\begin{array}{c}\text { Average } F \\
(\%) \text { in the } \\
\text { whole } \\
\text { pedigree }\end{array}$ & $\begin{array}{c}\text { Average } \\
\text { relatedness } \\
(\%)\end{array}$ & $\begin{array}{c}\text { Inbred } \\
\text { animals } \\
(\%)\end{array}$ & $\begin{array}{c}\text { Average } F \\
(\%) \text { of inbred } \\
\text { animals }\end{array}$ \\
\hline Ali & 1.53 & 1.09 & 0.73 & 10.97 & 9.98 \\
AM & 1.56 & 1.55 & 0.68 & 15.7 & 9.86 \\
AV & 1.08 & 0.48 & 0.26 & 3.7 & 13.27 \\
A-NI & 2.23 & 2.50 & 0.10 & 32.0 & 7.80 \\
BP & 0.81 & 0.25 & 0.35 & 1.73 & 14.22 \\
Mo & 1.22 & 2.20 & 0.30 & 16.5 & 13.36 \\
Pi & 2.97 & 1.60 & 1.58 & 48.3 & 3.33 \\
Say & 1.73 & 3.13 & 1.70 & 25.0 & 13.56 \\
\hline
\end{tabular}

generations. BP was the breed in the worst state of pedigree completeness level with a very low percentage of great-grandparents known. AV and BP have a similar aspect in Figure 1, but the complete generations equivalent of $\mathrm{AV}$ was 1.08 , instead of 0.81 for BP. The difference between these two breeds is that there were some animals, usually widely used sires, in the AV breed with a high number of equivalent generations, a fact not present in the BP breed.

For most of the breeds, the pedigree completeness level was higher in the dam pathway when considering recent generations, but it improved in the 
52

J.P. Gutierrez et al.

Alistana

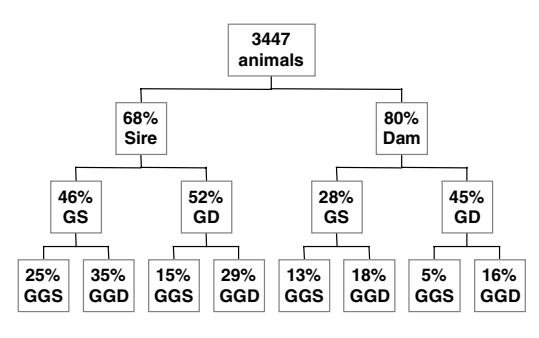

Avileña - Negra Ibérica

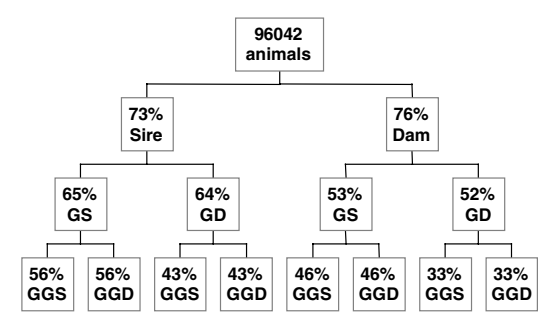

Buna dels Pirineus

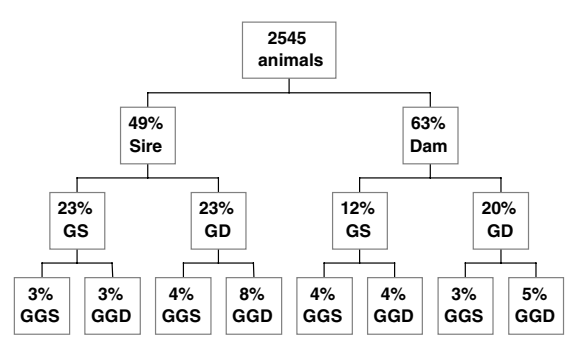

Pirenaica

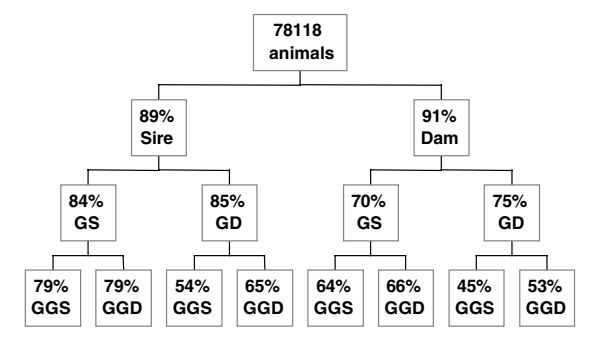

Asturiana de los Wales

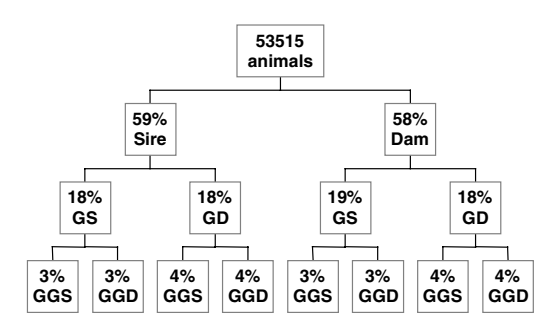

Asturiana de la Montaña

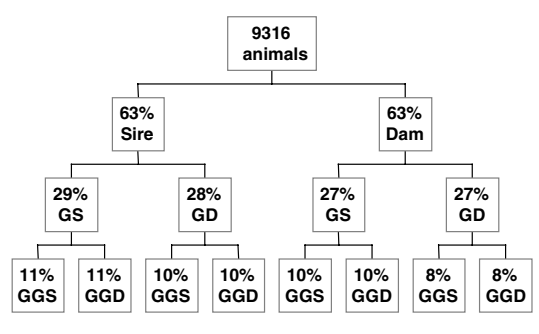

Morucha

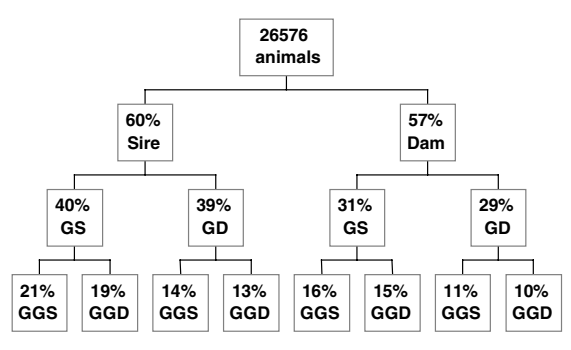

Sayaguesa

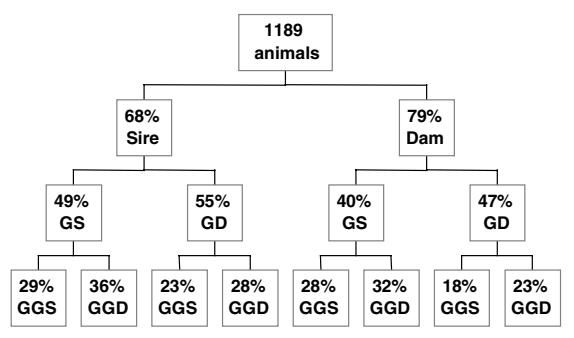

Figure 1. Pedigree completeness level in the whole pedigree data files, in eight Spanish beef cattle breeds.

sire pathway when the generations considered are distant. This could be a consequence of a good pedigree completeness level in the valuable sires of the 
Pi and A-NI breeds. The AV and AM breeds have a more balanced pattern between the sire and dam pathways where the percent of ancestor knowledge in the first generation was about $60 \%$.

\subsection{Inbreeding and average relatedness}

The average inbreeding value and the overall mean average relatedness $(A R)$ values in the whole pedigree are presented in Table IV. Since the inbreeding coefficient is a relative value that greatly depends on pedigree completeness level, the complete generation equivalents together with the percentage of inbred animals with its mean inbreeding value are also shown in Table IV. A graph describing the evolution of the inbreeding per year of birth, both in all animals and only in inbred animals, is drawn in Figure 2. The average coefficient of inbreeding was found to be variable among the different breeds. The breeds with the highest average inbreeding coefficient were Say, A-NI and Mo, followed by Pi and AM. The first of these breeds, Say, is the breed of the smallest census and has an acceptable pedigree completeness level. Thus, difficulties will be found when trying to avoid matings between relatives; this circumstance is reflected in the higher $A R$ coefficient in the breed studied, which shows a high degree of relationship among all the individuals in the pedigree.

The next two breeds in terms of comparatively higher inbreeding coefficient were A-NI and Mo. Their $A R$ coefficients, nevertheless, were very low, especially for the A-NI breed, showing the typical breeding management of the dehesa breeds in which the sires utilised are usually born in the same herd and the interchange of animals with other herds is not frequently carried out. In these breeds, there are subpopulations composed of several herds with an interchange of animals between them. In populations with low average relatedness, inbreeding would dramatically decrease if migration among subpopulations took place. The comparatively high inbreeding coefficient in the Pi breed was, however, related to the high degree of pedigree completeness level, which also led to a high $A R$ coefficient.

The percentage of inbred animals together with their average inbreeding coefficient were also computed, showing their evolution over the year of birth (Fig. 2). Common ancestors were rarely found when few generations were known and, thus, the percentage of inbred animals was very low. In our data, common ancestors belonged to very close generations in the pedigree, for which inbreeding coefficients were relatively high in their offspring. It will be noted in Figure 2 that the inbreeding coefficient of inbred animals decreases while the percentage of inbred animals and the inbreeding in the whole population increase. This is because the chance of finding common ancestors increases along with the pedigree completeness level, but these ancestors are found more in distant generations. The two breeds having the highest pedigree 

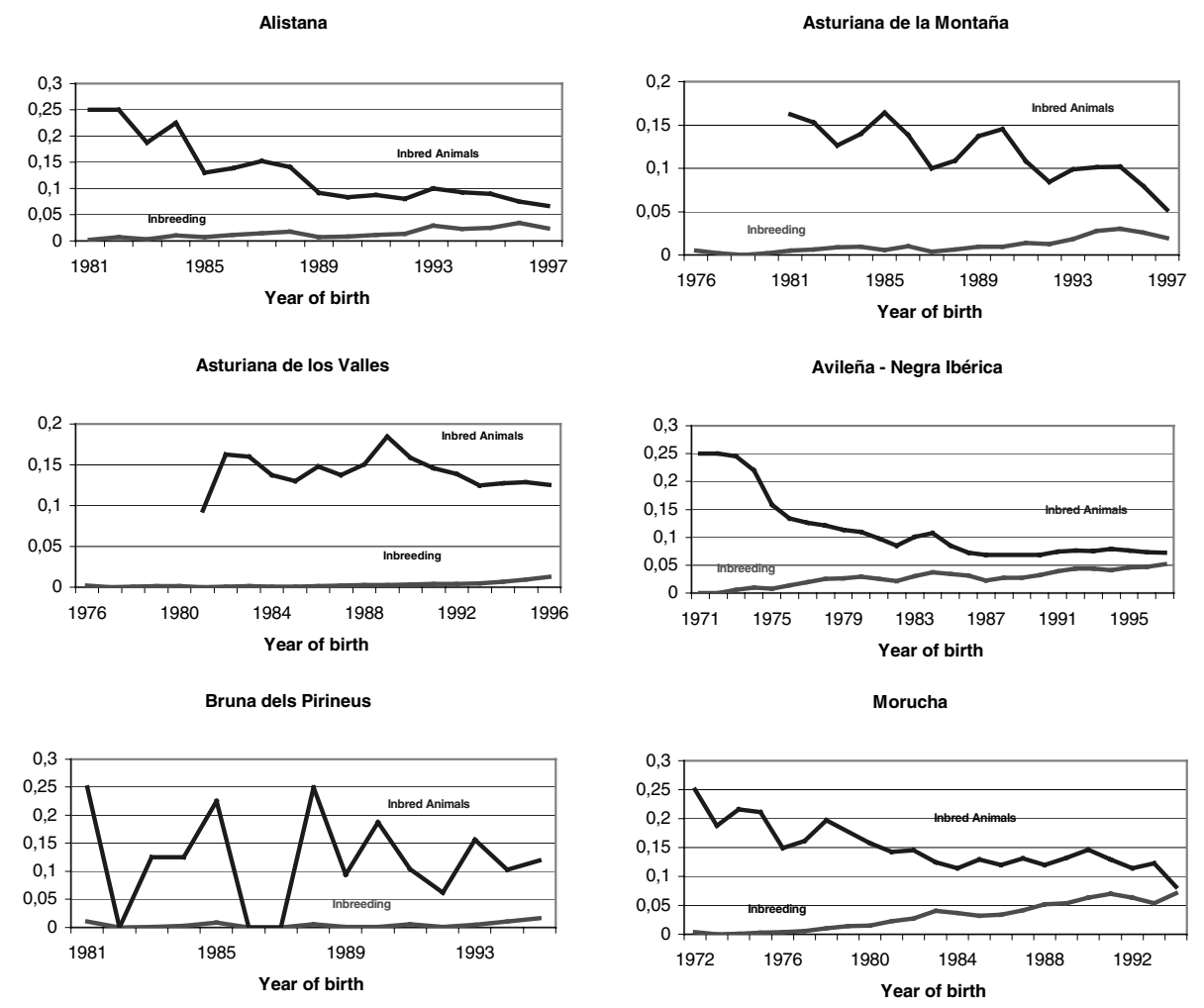

Pirenaica

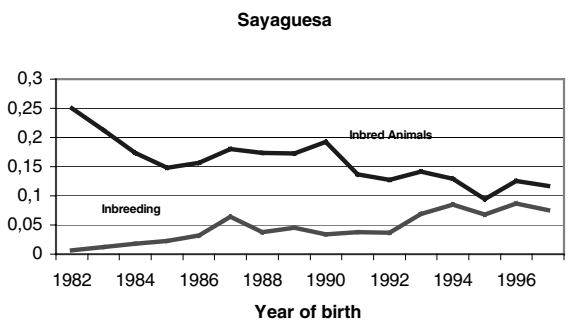

Figure 2. Evolution of inbreeding in the whole population and in inbred animals only, in eight Spanish beef cattle breeds.

completeness level were also those with the highest percentage of inbred animals, which present, in their turn, the lowest inbreeding coefficient of inbred animals. Conversely, the breed with the lowest pedigree completeness level, $\mathrm{BP}$, also had the highest inbreeding coefficient in inbred animals.

Only three breeds (AV, BP and Pi) showed an increase of the inbreeding per generation below 1\%, whereas Say surpassed $2 \%$ (Tab. V). The evolution of the coefficient of inbreeding is shown in Figure 2. In general, this coefficient 
Table V. Relative increase of inbreeding per year and generation, and estimates of effective population size in eight Spanish beef cattle breeds.

\begin{tabular}{lcccc}
\hline Breed & $\begin{array}{c}\text { Annual } \Delta F \\
(\%)\end{array}$ & $\begin{array}{c}\text { Average generation } \\
\text { interval }\end{array}$ & $\begin{array}{c}\Delta F \text { by generation } \\
(\%)\end{array}$ & $\begin{array}{c}N_{e} \\
(=1 / 2 \Delta F)\end{array}$ \\
\hline Ali & 0.3317 & 4.08 & 1.3539 & 36 \\
AM & 0.3087 & 4.55 & 1.4046 & 35 \\
AV & 0.1300 & 4.30 & 0.5590 & 89 \\
A-NI & 0.2170 & 5.70 & 1.2369 & 40 \\
BP & 0.0940 & 5.52 & 0.5200 & 95 \\
Mo & 0.3606 & 4.93 & 1.7762 & 27 \\
Pi & 0.0654 & 6.08 & 0.3973 & 123 \\
Say & 0.5867 & 3.75 & 2.2005 & 21 \\
\hline
\end{tabular}

tended to decrease. The Pi breed, though, showed a particular pattern. Its average inbreeding increased up to the decade of the nineteen fifties but then decreased to begin a new increase several years later. This could probably be due to the fact that matings were usually carried out within the herd up to the nineteen fifties until the use of AI sires began to spread the genes of a small number of bulls.

In order to distinguish between recent and cumulated inbreeding, the evolution of this parameter per year of birth was also computed taking into account only the last three generations (Fig. 3). All breeds exhibited a similar pattern showing that inbreeding was mainly due to the recent generations, in most of the cases because a historical knowledge of the pedigree is lacking. A-NI had an important cumulated inbreeding due to both a good knowledge of its historical pedigree and to the typical breeding management as a dehesa breed. The Pi breed, however, changed the usual breeding management with the use of AI in the last several years not showing much difference between the evolution of total inbreeding and that provided by only the last three generations considered.

\subsection{Effective population size}

The effective population size, $N_{e}$, is the number of breeding animals that would lead to the actual increase in inbreeding if they contributed equally to the next generation. In general, $N_{e}$ was rather low in the Spanish breeds, ranging from 21 to 123 (Tab. V). Again, the dehesa breeds were those with the lowest effective population size due to their particular intra-herd breeding policy. Subdivided populations can originate increases in inbreeding comparable to that of smaller populations. For mountain breeds, the larger breeds also showed the larger effective population size because of a dissemination of the more frequently used animals among herds. 

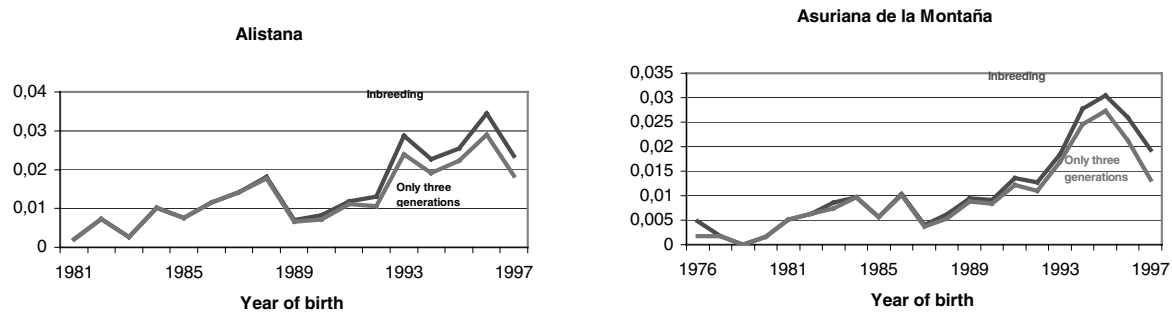

Asuriana de los Valles

Avileña - Negra lbérica
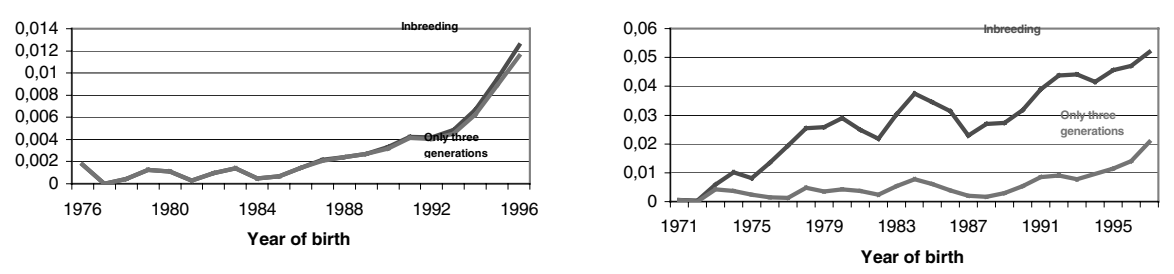

Morucha

Pirenaica
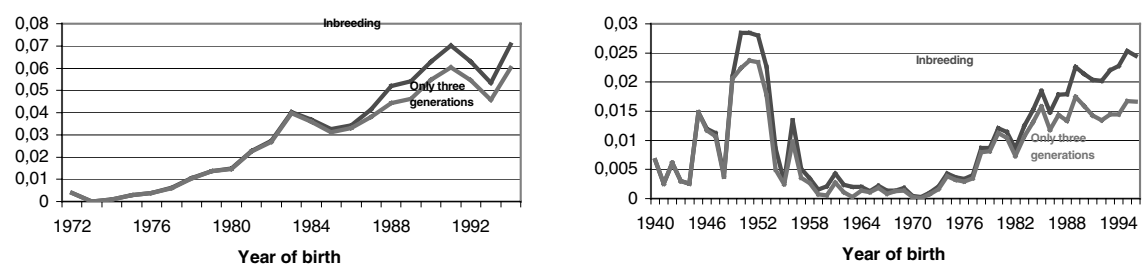

Sayaguesa

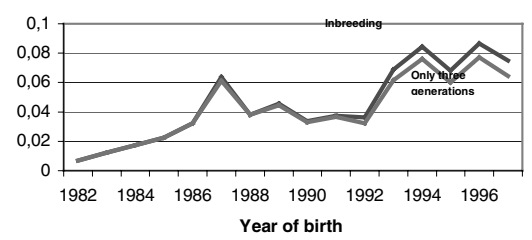

Figure 3. Evolution of inbreeding either with inbred ancestors or with three generations of ancestors only, in seven Spanish beef cattle breeds.

\subsection{Effective number of ancestors}

According to Boichard et al. [4], the parameters derived from the probabilities of gene origin are less sensitive to the pedigree completeness level than inbreeding parameters. The effective number of ancestors, the number of founder herds, the effective number of founder herds and the number of founders accounting for $50 \%$ of the genes of the population were computed. To perform the calculations, a reference population was defined as the animals born during the last three consecutive years of registered data. The years were variable depending upon the breed. 
These parameters explain how an abusive use of certain individuals as breeding animals can lead to a considerable reduction in the genetic stock. The upper bounds of these parameters are the actual number of founder animals/herds and they decrease since their contribution is more unbalanced.

Estimates for the parameters of gene origin are presented in Table VI, whereas the evolution of the percentage of the explained population by the number of ancestors considered is shown in Figure 4 for all breeds. As before, it is possible to find some differences among breeds in the pattern shown by each breed, which would be explained by different mating policies and would lead to different advice in terms of controlling future inbreeding and relatedness.

The effective number of founders and ancestors ranged from 48 to 846 and 25 to 163 , respectively. These values were higher in the larger populations, especially when the size of their founder population was initially high, and were not directly dependent upon the size of their populations of reference. In the larger breeds, the size of the founder population was large when the pedigree completeness level was sparse, as in the AV breed. In the minority breeds, when the genealogy knowledge was sparse, the size of the founder population was still higher than the reference population, even twice as much, due to the fact that animals with unknown ancestors automatically became founders.

The number of founders accounting for $50 \%$ of the population genes ranges from 10 to 43, except for AV. Eight-point-three percent of the founders accounted for half of the population in BP, but this number was considerably lower in the other breeds, mainly in those with a larger historical genealogy, as A-NI $(0.8 \%)$ and $\mathrm{Pi}(1.1 \%)$. It must be noted that these values indicate how much of the inbreeding is caused by an abusive use of certain founders through their descendants. The differences between the effective number of founders and the effective number of ancestors reflect the existence of bottlenecks in the pedigree of several breeds. Furthermore, a bottleneck is logically more frequent in populations with a long historical pedigree knowledge such as Pi. This comparison also reflects the existence of important bottlenecks in Ali, AV, Pi and Say.

The evolution of the number of founders accounting for different percentages of the populations can be observed in Figure 4. Breeds having the largest population sizes (AV, A-NI, Mo, Pi) had the largest size of the founder population and, consequently, showed a similar pattern. In the largest breeds, the number of ancestors that accounts for the population diversity increased very quickly at the beginning, but slower than in the other breeds later; in other words, several ancestors explained a high percentage of the population, but the rest of the population was explained by many others. This particular trend was more pronounced if the genealogy was well known (A-NI, Pi). On the contrary, minority populations (Ali, Say) as well as a breed with a sparse knowledge of genealogy (BP) tended to exhibit a more linear pattern than the other breeds. The extrapolation of these results to more generations in the past suggests 
Table VI. Estimates of parameters of probability of gene origin in eight Spanish beef cattle breeds.

\begin{tabular}{lrcccccr}
\hline Breed & $\begin{array}{c}\text { Reference } \\
\text { population }\end{array}$ & $\begin{array}{c}\text { Number of } \\
\text { founders }\end{array}$ & $\begin{array}{c}\text { Effective } \\
\text { number of } \\
\text { founders }\end{array}$ & $\begin{array}{c}\text { Effective } \\
\text { number of } \\
\text { ancestors }\end{array}$ & $\begin{array}{c}\text { Founders } \\
\text { explaining } \\
50 \%\end{array}$ & $\begin{array}{c}\text { Number of } \\
\text { founder herds }\end{array}$ & $\begin{array}{c}\text { Effective } \\
\text { number of } \\
\text { founder herds }\end{array}$ \\
\hline Ali & 513 & 1207 & 265 & 56 & 22 & 20 & 2 \\
AM & 307 & 1295 & 119 & 83 & 40 & 427 & 50 \\
AV & 16509 & 10107 & 846 & 163 & 415 & 2935 & 304 \\
A-NI & 13034 & 4301 & 68 & 59 & 36 & 137 & 59 \\
BP & 259 & 327 & 48 & 40 & 27 & & \\
Mo & 1193 & 990 & 130 & 105 & 43 & 225 & 76 \\
Pi & 8604 & 3279 & 153 & 58 & 36 & 615 & 54 \\
Say & 235 & 407 & 116 & 25 & 10 & 13 & 5 \\
\hline
\end{tabular}




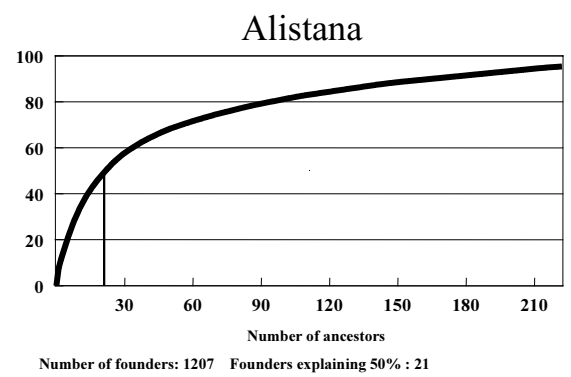

Asturiana de la Montaña

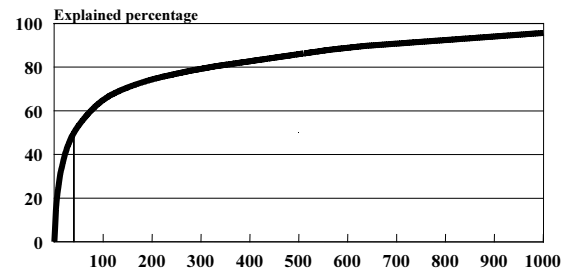

Number of founders: $1295 \quad \begin{aligned} & \text { Number of ancestors } \\ & \text { Founders explaining 50\% : } 40\end{aligned}$

Bruna dels Pirineus

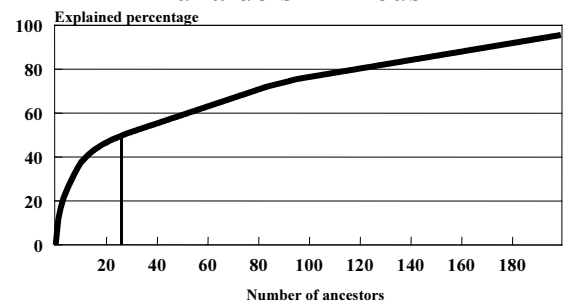

Number of founders: 199 Founders explaining $50 \%: 26$

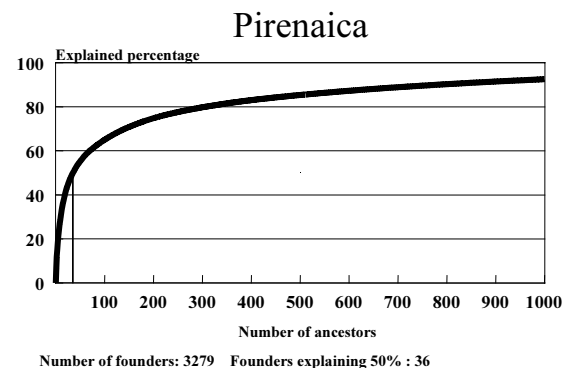

Asturiana de los Valles

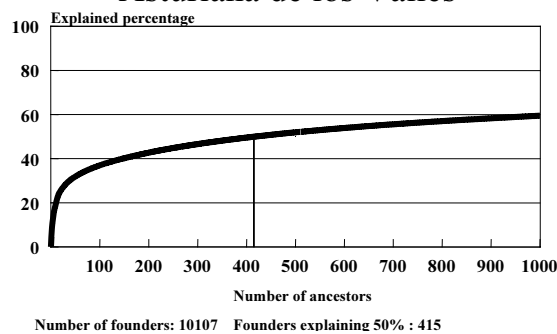

Avileña - Negra Ibérica

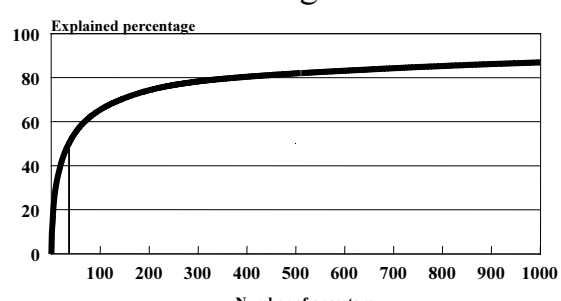

Number of founders: $4301 \quad \begin{gathered}\text { Number of ancestors } \\ \text { Founders explaining } 50 \%: 36\end{gathered}$

Morucha

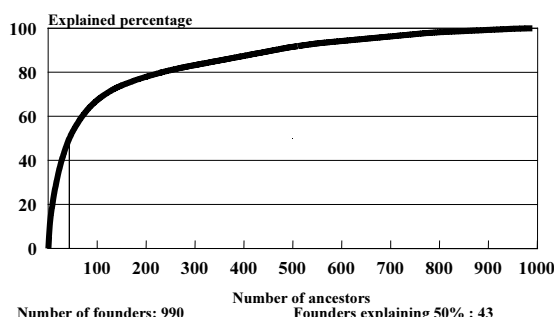

Sayaguesa

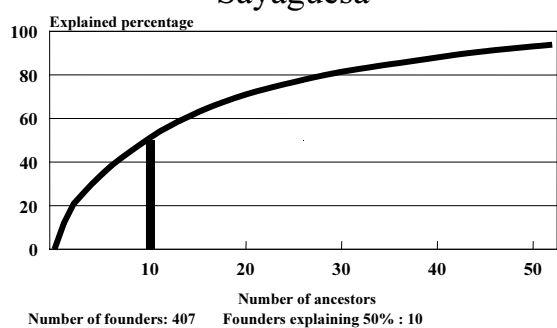

Figure 4. Cumulative contribution of the ancestors to the genes of the reference population, in eight Spanish beef cattle breeds.

that matings may have been carefully managed in small populations to avoid inbreeding consequences. 
The analysis of the number of founder herds and their effective number leads to similar conclusions in terms of abusive use of some breeding animals and loss of genetic diversity of populations. The effective number of founder herds in relation to the total number of founder herds, was clearly larger in the dehesa breeds (A-NI and Mo, around 40\%) than in the mountain breeds (AM, AV and $\mathrm{Pi}$, around $10 \%$ ). This difference could be due to the low rate of migration between herds in the dehesa breeds. Two of the minority breeds, Ali and Say, appeared equally founded by the animals of two and five herds, respectively, which indicates the potentially endangered state of these populations.

\section{DISCUSSION}

The estimates of generation intervals range from 3.70 to 6.08 years in the reference populations. In the sire-offspring pathway, the generation interval was always lower because sires were replaced earlier. A longer generation interval in females than in males has been previously reported in other breeds, for example, in Australian Shorthorn [11] or British Hereford [16], and also in A-NI [20], and AM and AV [8].

Inbreeding has been shown to have an adverse effect on all performance traits of beef cattle, although the effects of the inbreeding depression were more severe in populations developed under rapid inbreeding systems, and particularly in animals with inbreeding coefficients higher than 20\% [5]. In our populations, the average inbreeding was low, in the range of $1 \%$ to $3 \%$, so they can be considered far from dangerous values. Even the inbred animals in recent generations did not approach the limit mentioned above.

When looking at the future, however, the effective population size in general was rather low in the Spanish breeds, ranging from 21 to 123. In five breeds (Ali, AM, A-NI, Mo and Say) that parameter did not reach the minimum recommended value [14] to prevent a considerable loss of genetic variability. Boichard et al. [4] have shown that when the pedigree information is incomplete, the computed inbreeding is biased downwards and the realised effective size is overestimated. Given the very low degree of pedigree knowledge in most of the breeds studied, the true effective size would be even lower, which would worsen the situation in terms of maintenance of genetic variability.

Boichard et al. $[3,4]$ have also found low population sizes (below 50) in several French breeds, such as Holstein, Normande, and Tarentaise. Our results, however, cannot be compared to the results of these authors because the complete generation equivalent value was, in general, much lower in the Spanish breeds and the information used to estimate $\Delta F$ was different. Furthermore, these authors [4] have shown that the trend in inbreeding was very unstable between replicates of a simulation experiment, especially when the pedigree was not complete. Given the sparse pedigrees of most of the Spanish 
breeds studied, our estimates may have a high degree of uncertainty. It becomes evident that an intensive effort of pedigree recording will be needed in order to develop an appropriate monitoring of the genetic variability in most of the Spanish breeds. This situation is particularly critical for the Ali and Say breeds, in which a more indepth analysis of their population structure will allow for the establishment of optimal criteria for choosing and mating the breeding animals.

Migrations between subpopulations when there is a low average relatedness value, i.e. in dehesa breeds, in order to dramatically decrease inbreeding has a logical appeal. This strategy should be tested in the future in different scenarios against the results that can be obtained by different mating methods, such as factorial and compensatory matings (see review of Caballero et al. [6]), or minimum coancestry mating with a maximum of one offspring per mating pair [18].

The effective number of ancestors takes into account the possible bottlenecks in the pedigree, such as those originated by AI schemes, and, thus, this parameter tends to present values lower than the effective number of founders (Boichard et al. [4]). This parameter will be equivalent to the average pairwise coancestry of a given group of $N$ individuals (see equation (5) in [7]). Usually, historical pedigrees tend to provide low values of both effective numbers of founders and ancestors. When we compared the effective number of founders to the effective population size, and the effective number of founder herds in contrast to the $H_{S}$ parameter that measures the effective number of herds supplying sires per generation, BP appeared to be the breed with the lowest effective number of founders and ancestors, but it ranked second in terms of the effective population size estimated from the increase of inbreeding per generation. This figure, nevertheless, could be related to the low completeness level of the pedigree. On the contrary, Ali had approximately the same effective number of founders as $\mathrm{AV}$, but the number of effective founder herds was 2 for Ali against 304 for AV. The breed with the highest pedigree completeness level (Pi) had a discrete effective number of founders but the highest effective population size and a very low effective number of founder herds. Each group of breeds was shown to have its own particular pattern regarding all the parameters analysed and, even within group, each breed was shown to have its own particular situation.

\section{CONCLUSIONS}

The main conclusion to be drawn from our study is that the genetic status regarding the maintenance of genetic variability differs among breeds, and a single practical recommendation does not exist. The causes of these differences could be related to population size, breeding policy, and probably in some breeds to empirical selection objectives. 
The subdivision carried out at the beginning of this paper leads to different conclusions for the dehesa versus the mountain breeds. Inbreeding is higher in the dehesa breeds than in the mountain breeds, whereas the opposite is true for average relatedness.

There is clear evidence that Ali and Say populations have a small effective size from a genetic point of view. As a consequence, a more indepth analysis of the genetic structure of each breed and its mating policy is necessary in order to recommend, on an individual basis, the most convenient breeding practices to maintain genetic diversity. The A-NI and Mo breeds, with a small effective size but showing a low mean average relatedness coefficient, are not in danger.

Most of the breeds need an important recording effort in order to achieve better genealogy knowledge, particularly $\mathrm{AV}, \mathrm{BP}$ and $\mathrm{Mo}$, and to be able to properly carry out the monitoring of inbreeding. This situation is critical for BP because the two other breeds have animals which have made an important contribution to the population and with a well known genealogy. Pi is different from the others, presenting a wide historical pedigree.

The effective number of founders is considerably higher than the effective number of ancestors in mountain and minority breeds when compared to dehesa breeds, as a consequence of their particular breeding system.

\section{ACKNOWLEDGEMENTS}

This research has been funded by the EU - FAIR1 CT95 0702 and AGF950576 projects, the last one granted by the "Comision Interministerial de Ciencia y Tecnología" of the Spanish government. We acknowledge the collaboration of the breed societies for recording and providing the data. The English of this manuscript was revised and corrected by Chuck Simmons, instructor of English at the UAB.

\section{REFERENCES}

[1] Altarriba J., Ocáriz J.M., Estudio genético-reproductivo de la raza Pirenaica a partir del registro genealógico de Navarra, ITEA 7 (1987) 67-69.

[2] Ballou J.D., Lacy R.C., Identifiyng genetically important individuals for management of genetic variation in pedigreed populations, in: Ballou J.D., Gilpin M., Foose T.J. (Eds.), Population management for survival and recovery, Columbia University Press, New York, 1995, pp. 76-111.

[3] Boichard D., Maignel L., Verrier E., Analyse généalogique des races bovines laitières françaises, INRA Prod. Anim. 9 (1996) 323-335.

[4] Boichard D., Maignel L., Verrier E., The value of using probabilities of gene origin to measure genetic variability in a population, Genet. Sel. Evol. 29 (1997) 5-23. 
[5] Burrow H.M., The effects of inbreeding in beef cattle, Anim. Breed. Abstr. 61 (1993) 737-751.

[6] Caballero A., Santiago E., Toro M.A., Systems of mating to reduce inbreeding in selected populations, Anim. Sci. 62 (1996) 431-442.

[7] Caballero A., Toro M.A., Interrelations between effective population size and other pedigree tools for the management of conserved populations, Genet. Res. Camb. 75 (2000) 331-343.

[8] Cañón J., Gutiérrez J.P., Dunner S., Goyache F., Vallejo M., Herdbook analysis of the Asturiana beef cattle breeds, Genet. Sel. Evol. 26 (1994) 65-75.

[9] Dunner S., Checa M.L., Gutiérrez J.P., Martín J.P., Cañón J., Genetic analysis and management in small populations: the Asturcon pony as an example, Genet. Sel. Evol. 30 (1998) 397-405.

[10] Falconer D.S., Mackay T.F.C., Introduction to Quantitative Genetics, Longman, Harlow, 1996.

[11] Herron N.D., Pattie W.A., Studies of the Australian Illawarra Shorthorn breed of dairy cattle. II., Austr. J. Agric. Res. 28 (1977) 1119-1132.

[12] James J.W., Computation of genetic contributions from pedigrees, Theor. Appl. Genet. 42 (1972) 272-273.

[13] Lacy R.C., Analysis of founder representation in pedigrees: founder equivalents and founder genome equivalents, Zoo. Biol. 8 (1989) 111-123.

[14] Meuwissen T.H.E., Operation of conservation schemes, in: Oldenbroek J.K. (Ed.), Genebanks and the conservation of farm animal genetic resources, DLO Institute for Animal Science and Health, Lelystad, 1999, pp. 91-112.

[15] Meuwissen T.H.E., Luo Z., Computing inbreeding coefficients in large populations, Genet. Sel. Evol. 24 (1992) 305-313.

[16] Özkütük K., Bichard M., Studies of pedigree Hereford cattle breeding. 1. Herdbook analyses, Anim. Prod. 24 (1977) 1-13.

[17] Robertson A., A numerical description of breed structure, J. Agric. Sci. 43 (1953) 334-336.

[18] Sonesson A.K., Meuwissen T.H.E., Non-random mating for selection with restricted rates of inbreeding and overlapping generations, Genet. Sel. Evol. 34 (2002) 23-29.

[19] United Nations Environment Programme, Convention on Biological Diversity, Environmental Law and Institutions Programme Activity Centre, 1992, pp. 1-52.

[20] Vassallo J.M., Díaz C., García-Medina J.R., A note on the population structure of the Avileña breed of cattle in Spain, Livest. Prod. Sci. 15 (1986) 285-288.

[21] Verrier E., Colleau J.J., Foulley J.L., Le modèle animal est-il optimal à moyen terme ?, in: Foulley J.L., Molénat M. (Eds.), Séminaire modèle animal, Inra, Paris, 1994, pp. 57-66.

[22] Vu Tien Kang J., Méthodes d'analyse des données démographiques et généalogiques dans les populations d'animaux domestiques, Génét. Sél. Évol. 15 (1983) 263-298.

[23] Wright S., Mendelian analysis of the pure breeds of livestock. I. The measurement of inbreeding and relationship, J. Hered. 14 (1923) 339-348.

[24] Wright S., Evolution in Mendelian populations, Genetics 16 (1931) 97-159. 